\title{
INOVASI STRATEGI PEMBELAJARAN BAHASA ARAB MAHARAHISTIMA'
}

\section{Widi Astuti}

Sekolah Tinggi Agama Islam Masjid Syuhada Yogyakarta

Widychuby1990@gmail.com

\section{Abstrak}

Strategi pembelajaran adalah bagian dari keterampilan dalam mendesain segala kegiatan pembelajaran dalam kelas, strategi pembelajaran bahasa merupakan kegiatan pendidik dalam merancang rencana pembelajaran dan strategi menyimak adalah seni mendesain semua kegiatan di dalam kelas untuk meningkatkan kemampuan menyimak peserta didik. Pembelajaran akan efektif dan efisien jika didukung oleh strategi pengembangan keterampilan pendidik. Cara pendidik dalam mengatur strategi pembelajaran sangat berpengaruh terhadap cara belajar peserta didik. Sebagaimana kreteria untuk memilih strategi pembelajaran antara lain: adanya tujuan pembelajaran, metode dan strategi, media yang digunakan, system evaluasi, peserta didik, dan juga pendidik sebagai pelaksana pembelajaran.

Oleh karena itu beberapa strategi akan disajikan dengan tujuan memberikan solusi alternative dalam menghadapi problematika pembelajaran bahasa Arab. Melalui paparan inovasi strategi pembelajaran bahasa Arab akan memudahkan pendidik sebagai fasilitator dalam menyampaikan materi yang akan disampaikan kepada peserta didik dengan baik sesuai dengan tujuan pembelajaran

Kata kunci: inovasi pembelajaran, keterampilan menyimak, menyimak.

\section{Abstract}

Learning strategy is an art of designing all learning activities in the classroom. Language learning strategy is teacher's activities 
concerninghis/her lesson plan; and listening learning strategy is an art of designingalllearning activities in the classroom for improving students'listeningcompetence.Learning will take place effectively and efficiently if supported by teacher skill set learning strategy. The way teachers organize learning strategies is very influential to the way learners learn.As criteria to choose learning strategythere are: learning goal, skill at lesson, media being used, evaluation system, and student as subjectand teacher as implementer.

Therefore, some strategies will be presented with the aim of providing alternative solutions in dealing with Arabic teaching problematics. With the exposure of innovation Arabic learning strategies, will facilitate the teachers as a medium of conveyance of the material to be conveyed to the students well according to the purpose of learning.

Keywords: innovation of learning, language learning strategies, listening strategies

\section{A. PENDAHULUAN}

Strategi adalah salah satu komponen kurikulum yang menjadi perhatian didalam proses pembelajaran. Nana Sudjana mengatakan bahwa strategi belajar-mengajar merupakan tindakan gurumelaksankan rencana mengajar, yaitu usaha guru dalam menggunakan beberapa variabelpengajaran (tujuan, metode, alat, serta evaluasi) agar dapat mempengaruhi siswa mencapai tujuanyang telah ditetapkan. ${ }^{34}$ Berbeda dengan pendapat dari salahsatu penulis yang menyatakan bahwa strategi sebagai kemungkinan variasi, yakni sekuensi umumtindakan pengajaran yang secara prinsipil berbeda 1989), hal. 147.

${ }^{34}$ Nana Sudjana,Dasar-Dasar Proses Belajar-Mengajar(Bandung: Sinar Baru, 
antara yang satu dengan yang lain. ${ }^{35}$ Sukses atau tidaknya suatu program pengajaran bahasa Arab juga menjadi pengaruh dari strategi pengajaran yang digunakan, karena strategi merupakan alat tercapainya isi dan cara mengajarkan bahasa Arab. Fenomena yang banyak bermunculan di ranah pengajaran yang berkaitan dengan penyajian strategi paling inovatif juga bermunculan di lembaga-lembaga baik formal maupun non formal, bahkan beberapa dari lembaga-lembaga tersebut berlomba-lomba menggunakan strategi pengajaran yang terbaik dan selalu inovatif.

Di lain pihak, ada beberapa pendapat yang berlawanan dengan kenyataan yang telah disampaikan pada paragraf sebelumnya, yang menyatakan bahwa strategi itu tidaklah penting dan bukan yang utama. Ada faktor-faktor lain yang lebih dominan dalam menilai keberhasilan pembelajaran yakni potensi dan kualitas peserta didik itu sendiri. Pendapat lain menyebutkan bahwa strategi sebatas sebagai alat saja dan pengajar yang lebih berpengaruh dan menentukan berhasil atau tidaknya suatu pengajaran. Terlepas dari hal-hal yang telah disebutkan di atas, tidak dapat dipungkiri bahwa setiap saat pengajar dihadapkan dengan strategi baru atau diminta meninjau kembali strategi yang dipakai pada proses belajar mengajar.

35Sunhaji, Insania: "Strategi Pembelajaran: Konsep dan Aplikasinya", (STAIN Purwokerto:, 2008, Volume 13, Nomor.3), hlm. 1. 
Oleh karena itu, beberapa strategi akan dipaparkan dengan tujuan dapat memberikan solusi alternatif dalam menghadapi problematika pengajaran bahasa Arab. Dengan pemaparan inovasi strategi-strategi pembelajaran bahasa Arab, akan mempermudah pengajar sebagai media penyampai materi agar tersampaikan kepada peserta didik dengan baik sesuai tujuan dari pembelajaran.

Berdasarkan filsosofi bahwa mengajar yang baik adalah bukan sekedar mentransfer pengetahuan kepada peserta didik, akan tetapi juga membantu mereka untuk belajar secara mandiri dan bertanggungjawab. Selain itu, Berdasarkan prinsip student centered, peserta didik merupakan pusat dari suatu kegiatan belajar. Hal ini dikenal dengan istilah CBSA (Cara Belajar Siswa Aktif) sering diterjemahkan dari SAL(student active learning), yang maknanya adalah ikhwal proses pembelajaran akan lebih berhasilapabila peserta didik secara aktif melakukan latihan secara langsung dan relevan dengan tujuanpembelajaran yang sudah ditetapkan (Dick dan Carey, 1978). ${ }^{36} \mathrm{Hal}$ tersebut menegaskan bahwa pengajar tidak lagi menjadi pemeran utama atau sentral dalam kegiatan belajar mengajar, namun lebhi kepada pengajar sebgai fasilitator yang menfasilitasi peserta didiknya untuk memahami materi melalui hasil belajarnya sendiri.

36Dick Walter \& Carey Lou,The Systematic Desgn of Instruction(New York: Harper Collins publishers, 1994), hal.3. 
Disamping itu, inovasi strategi pembelaajaran juga akan membantu peserta didik untuk aktif belajar menemukan dan memecahkan masalahnya sendiri, menemukan ide pokok dari pembahasan materi, dan berperan aktif dalam berjalannya proses belajar mengajar. Dengan cara ini, maka suasana belajar akan lebih bermakna dan menyenangkan serta tujuan pembelajaran akan tercapai.

\section{B. PEMBAHASAN}

Pemilihan strategi pembelajaran yang akan digunakan dalam proses pembelajaran harusberorientasi pada tujuan pembelajaran yang akan dicapai. Selain itu juga harus disesuaikan denganjenis materi, karakteristik peserta didik, serta situasi atau kondisi di mana proses pembelajarann tersebut akan berlangsung. Terdapat beberapa metode dan teknik pembelajaran yang dapatdigunakan oleh guru, tetapi tidak semuanya sama efektifnya dapat mencapai tujuan pembelajaran. Mager (1977) menyampaikan beberapa kriteria yang dapat digunakan dalam memilih strategipembelajaran, yaitu sebagai berikut. 1. Berorientasi pada tujuan pembelajaran. Tipe perilaku apa yang diharapkan dapat dicapai olehpeserta didik, misalnya menyusun bagan analisis pembelajaran. Hal ini berarti metode yang palingdekat dan sesuai yang dikehendaki oleh TPK adalah latihan atau praktik langsung. 2. Pilih teknik pembelajaran sesuai dengan keterampilan yang diharapkan 
dapat dimiliki saatbekerja nanti (dihubungkan dengan dunia kerja). Misalnya setelah bekerja, peserta didik dituntutuntuk pandai memprogram data komputer (programmer). Hal ini berarti metode yang palingmungkin digunakan adalah praktikum dan analisis kasus/pemecahan masalah (problem solving). 3. Gunakan media pembelajaran yang sebanyak mungkin memberikan rangsangan pada indrapeserta didik. Artinya, dalam satuan-satuan waktu yang bersamaan peserta didik dapat melakukanaktivitas fisik maupun psikis, misalnya menggunakan OHP. Dalam menjelaskan suatu bagan, lebihbaik guru menggunakan OHP daripada hanya berceramah, karena penggunaan OHPmemungkinkan peserta didik sekaligus dapat melihat dan mendengar penjelasan guru. ${ }^{37}$

Beberapa pendapat menyebutkan bahwa pembelajaran bahasa Arab Maharah Istima' tidak perlu adanya latihan karena keterampilan tersebut akan dikuasai dengan sendirinya tanpa adanya latihan sebagaimana halnya berjalan dan berbicara pada masa anak-anak. Maharah Istima' juga merupakan kegiatan yang menyertai Maharah lainnya (Maharah Kalam, Maharah Qiraah, dan Maharah Kitabah). Namun pada kenyataannya berdasarkan hasil penelitian ilmiah menyebutkan bahwa 30\% saja dari pengetahuan yang didengar

${ }^{37}$ Lihat Syamsul Bakhri dan Djamarah, Strategi Belajar mengajar (Jakarta: Rineka Cipta 1997), hal. 15. Lihat juga TIMFIP IKIP Semarang,Strategi belajar Mengajar, hal. 10

74 Jurnal Komunikasi dan Pendidikan Islam, Volume 1, Nomor 1, Juni 2018 
dan hanya dapat mengingat $25 \%$ dari apa yang ia serap dari pengetahuan tersebut. Oleh karena itu, untuk dapat meningkatkan daya serap pengetahuan yang didengarnya maka perlu adanya latihan untuk menguasai Maharah Istima'.

Adapun pembelajaran Maharah Istima' dibagi menjadi dua macam.

1. Menyimak untuk keperluan pengulangan (drill). Maharah Istima' pada model ini menuntut peserta didik untuk menyimak teks yang diperdengarkan baik melalui media audio, rekaman atau pengajar secara langsung kemudian mengulang dari apa yang didengarnya. Pada pembelajaran Maharah Istima' model ini, pengajar tidak disarankan untuk memperlambat atau mempercepat bacaan melampau batas yang seharusnya, sehingga peserta didik akan terbiasa dengan situasi belajar dengan model tersebut.

2. Menyimak untuk keperluan memahami teks. Peserta didik menyimak teks dengan tujuan memahamiterks tersebut dengan baik, dapat membedakan antara ide pokok, dan kalimat penjelas, serta dapat memahami alur cerita dalam teks dan sebagainya.

Selanjutnya Dick dan Carey (1978) menyebutkan bahwa terdapat 5 komponen strategi pembelajaran, yaitu (1) kegiatan pembelajaran pendahuluan, (2) penyampaian 
informasi, (3) partisipasi peserta didik, (4) tes, dan (5) kegiatan lanjutan. ${ }^{38}$

Adapun inovasi strategi pembelajaran bahasa Arab Maharah Istima' antara lain sebagai berikut: ${ }^{39}$

a. Ta'lim Muta'awin تعليم متعاو

Strategi ini digunakan untuk mengetahui cara yang paling efektif dan inovatif bagi pemahaman peserta didik. Secara umum, strategi ini memberikan peluang atau kesempatan kepada peserta didik untuk saling berbagi dan bertukar hasil belajar dari materi yang sama dengan cara berbeda dengan membandingkan catathan hasil belajar dari masing-masing peserta didik.

Langkah-langkah yang harus dtempuh dalam strategi ini adalah sebagai berikut:

1) Peserta didik dibagi menjadi 2 kelompok dan ditempatkan dalam 2 tempat terpisah.

2) Pengajar membacakan dan menjelaskan teks yang diajarkan. Contok teks yang berjudul" 40 pada kelompok I, sedangkan untuk kelompok II pengajar menceritakan teks tersebut dengan bahasa pengajar senidiri melalui metode ceramah.

\footnotetext{
${ }^{38}$ Dick Walter \& Carey Lou,The Systematic Design of Instruction(New York: Harper Collins publishers, 1994), hal.3.

${ }^{39}$ Zaenuddin Radliyah, dkk, Metodologi dan Strategi Alternatif Pembelajaran Bahasa Arab, (Yogyakarta: Pustaka Rihlah Group, 2005), hlm. 51.

${ }^{40} \mathrm{Kitab}$ Al-Arabiyah li al-Nasyiin, jilid II
} 
Setelah selesai peserta didik dikumpulkan dan masing-masing dari anggota kelompok I diminta mencari pasangan dari anggota kelompok II. Masing-masing pasangan diminta untuk menggabungkan hasil belajar dan dapat menjawab pertanyaan-pertanyaan pengajar seputar isi teks.

b. Talkhis Magzaیزيص مغز

Strategi ini dapat menguji kemampuan menyimak peseta didik terhadap isi teks cerita. Jawaban peserta didik terhadap pertanyaan من فعل, لماذا, كيف, أين, مني, لمن, ماذا فعل؟ yang kemudian disintesiskan kedalam satu kalimat singkat, padat dan jelas sehingga dapat mengembangkan daya berpikir peserta didik dengan kreatif kritis dan inovatif terhadap topik yang disajikan.

Langkah-langkah yang yang harus ditempuh dalam inovasi strategi ini adalah sebgai berikut:

1) Pilihlah satu tema pembahasan yang belum pernah diberikan dan dipelajari peserta didik.

2) Pengajar menjelaskan peraturan yang harus ditaati dan dikerjakan peserta didik. Yakni peserta didik diminta untuk mencatat hal-hal yang berkaitan dengan jawaban beberapa pertanyaan terkait.

3) Kemudian pengajar menjelaskan satu tema dan peserta didik cukup menyimak. 
4) Pada saat menyimak, peserta didik diminta untuk menjawab pertanyaan-pertanyaan yang telah dicatat dan menggabungkan jawaban dari pertanyaan-pertanyaan tersebut dalam satu kalimat wacana. Sebagai contoh, pengajar menyajikanteks yang berjudul"41" إصلاح الدين

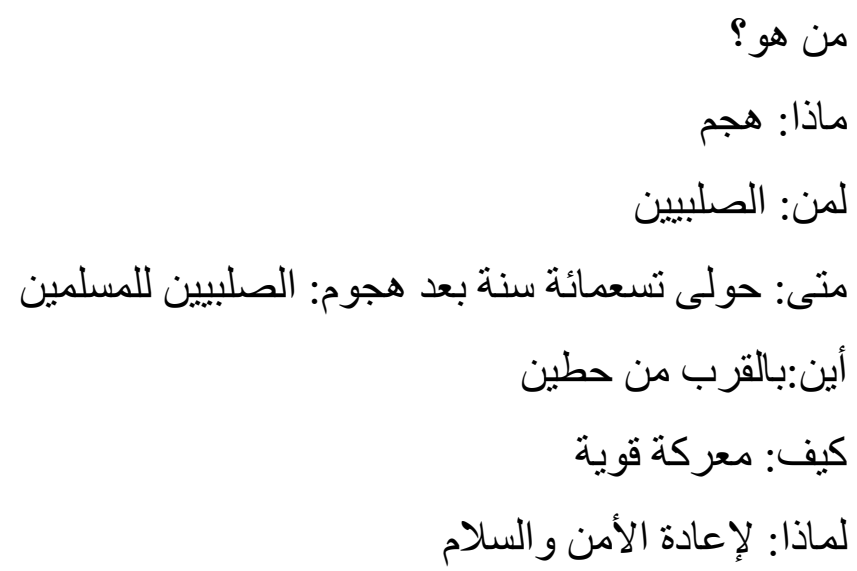

5) Pengajar kemudian memberi waktu yang cukup bagi peserta didik untuk menganalisa dan merangkum pertanyaan tersebut menjadi satu kalimat ringkasan.

6) Pengajar mengembalikan hasil evaluasi kepada peserta didik, dan terus memberi motivasi bagi yang belum tepat dalam menjawab.

c. Istima' mutabadil إستماع متبادل

Salahsatu inovasi dari strategi ini adalah dapat mengarahkan peserta didik untuk fokus dan konsentrasi

${ }^{41} \mathrm{Kitab}$ Al-'Arabiyyah Li An-Nasyi'in, jilid III hal.65 
terhadap materi yang disampaikan. Langkah-langkah yang harus ditempuh pada strategi ini antara lain sebagai berikut:

1) Peserta didik dibagi menjadi tiga kelompok, setiap kelompok memiliki tugas yang berbeda yaitu sebgai penanya, kontra penentang dan pro- pendukung.

2) Pengajar menyampaikan satu topik yang materinya menngandung unsur-unsur kontroversi, contohnya

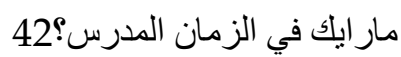

3) Pada saat menyimak teks yang diperdengarkan, masing-masing kelompok melaksanakan tugasya yaitu kelompok penanya bertugas siap-siap membuat pertanyaan yang berkaitan dengan teks yang dibicarakan oleh pengajar.

Sedangkan kelompok kontra mencoba membuat argumentasi yang menafikan diskursus yang sedang dibahas.

Dan kelompok pro melakukan hal sebaliknya. Yakni menyusun argumentasi yang menguatkan diskursus yang sedang dibahas.

4) Menyediakan waktu yang cukup bagi peserta didik untuk melakukan aktivitas pembelajaran. Setelah waktu yang telah ditentukan selesain pengajar

42Kitab Al-'Arabiyyah li Al-Nasyi'in jilid III hal. 211. 
meminta peseta didik merapikan kursi menjadi tiga kelompok yang saling berhadapan.

Kemudian mintalah masing-masing kelompok menyampaikan hasil dari tugas mereka. Dan mengevaluasi serta mengarahkan tema pembahasan.

d. Istima' Al-Ghaniy إستماع الغانى

Inovasi dari strategi ini yakni membantu peserta didik untuk selalu aktif dan teliti serta cermat dan tepat dalam memahami dan memaknai syair dan melagukannya.

Langkah-langkah yang harus dilaksanakan dalam inovasi strategi ini adalah tahap persiapan yakni menyediakan kaset lagu berbahasa resmi fusha dan kisikisi berupa potongan syair lagu. Selanjutnyatahap pelaksaanaan kisi-kisi tersebut dibagikan kepada peserta didik, dan satu lagu diperdengarkan peserta didik diminta untuk melengkapi potongan lagu yang tidak lengkap tersebut. Tahap pemantapan yakni lagu diputar kembali, namun diperdengarkan kepada peserta didik secara per baris atau per bait tergantung kemampuan menyimak masing-masing peserta didik. Setiap selesai per lagu yang diperdengarkan, tape recorder dimatikan, kemudian peserta didik diminta ditanya isi materi dari kisi-kisi yang kosong yang 
Widi Astuti : Inovasi Strategi Pembelajaran Bahasa Arab Maharahistima'

dimaksud. Terahir melakukan evaluasi bersama dengan peserta didik lainnya.

Setelah tahap pelaksaanaan dan pemantapan, peserta didik diarahkan untuk membahas tema dan isi lagu, serta membenarkan cara penulisan mereka.

e. Istima' Al-Ma'lumat Au Al-Akhbar إستماع المعلومات أو الأخبار

Inovasi strategi ini menekankan bahwa konsentrasi peserta didik akan terpusat untuk tetap utuh meskipun dalam rentang waktu yang cukup lama. Peserta didik dapat menyimak dan memahami dengan baik dari sebuah informasi, baik dari segi keruntutan bahasanya dan tingkat komunikasinya.

Langkah-langkah yang harus dilaksanakan dalam inovasi strategi ini adalah sebagai berikut:

1) Mempersiapkan tape recorder dan kaset yang berisi materi yang disajikan baik dari berita, pidato ataupun informasi lainnya yang berbahasa Arab resmi Fusha. ${ }^{43}$

\footnotetext{
43Bahasa Arab Fusha yaitu; Sering disebut bahasa Al Qur'an, (( اللغة التراث atau bahasa yang sering dipergunakan diforum formal, bahasa buku, syi'ir dan nasr dan juga dipakai pada produk-produk, ilmu pengetahuan dan hasil-hasil pemikiran. Bahasa Arab Fusha yaitu bahasa pemersatu dan bahasa yang dapat menyelesaikan perselisihan antara bangsa-bangsa Arab. Karena dengan bahasa Arab Fusha, orang-orang dapat memahami dan berkomunikasi dengan lancar asalkan bahasa yang digunakan adalah bahasa Arab Fusha yang sesuai dengan kaidah-kaidah ilmu nahw, sharf dan balaghah. Bahasa Arab Fushah ini digambarkan sebagai bahasa Arab yang digunakan terhadap masyarakat pada zaman Rasulullah SAW. Bahasa Arab Fushah ini adalah media pokok komunikasi yang digunakan dalam bentuk buku-buku, majalah, surat menyurat dan surat pribadi, dokumen pemerintahan dan digunakan juga pada media televisi, radio, dan pidato-pidato serta konferensi-
} 
2) Kaset yang berisi materi yang diambilkan dari beberapa informasi tersebut diputar dan peserta didik diminta untuk menyimak dan mencatat poinpoin penting yang ada pada materi yang diperdengarkan tersebut.

3) Membagi peserta didik menjadi beberapa kelompok dan setiap kelompok diberikan tugas untuk meninjau ulang dengan menulis hasil isi materi yang diperdengarkan serta mendiskusikannya dengan peserta didik yang lain.

4) Kemudian peserta didik diminta untuk mempresentasikan hasil diskusi tersebut.

5) Melakukan evaluasi bersama dengan memutar kembali $C D$ atau kaset yang berisi materi yang telah diperdengarkan kepada peserta didik sebelumnya.

6) Setelah mengevaluasi bersama, maka tugas dari pengajar adalah membenarkan cara penulisan peserta didik.

konferensi dan seminar-seminar ilmiah bahkan menjadi bahasa pengantar disebagian "اللغة العالمية " (bahasa internasional) yang diresmikan pada 18 Desember 1982 oleh ; Organisasi Pendidikan,Keilmuan, dan Kebudayaan, yang dalam bahasa Inggris disebut sebagai UNESCO (United Nation Education,Scientific and Cultural Organization) dan menetapkan tanggal tersebut sebagai hari bahasa Arab sedunia. Maka dari itu bahasa standar inilah bahasa yang digunakan dinegara-negara Arab dan bermayoritas muslim didunia. Artikel ini dikutip dari http://ithla-id.blogspot.co.id/2016/02/perbedaanfushah-dan-amiah-dalam-bahasa.html diakses pada tanggal 09 Desember 2017 pukul 21.00 wib. 


\section{f. Istima' Al-Musykilat/إستماع المشكلات}

Inovasi dari strategi ini adalah untuk meningkatkan rasa empati peserta didik terhadap peserta didik lainnya. Peserta didik dapat memahami apa yang dialami oleh peserta didik lainnya dan memberikan solusi dalam menyelesaikan permasalahannya.

Langkah-langkah yang dilaksanakan pada inovasi strategi ini adalah antara lain sebagai berikut:

1) Peserta didik diminta berpasang-pasangan.

2) Peserta didik diminta untuk saling menyampaikan permasalahan yang dihadapinya kepada pasangannya.

3) Menyimak secara bergantian dan memberikan solusi dari permasalahan yang dihadapi oleh keduanya serta menuangkannya dalam bentuk tulisan.

4) Hasil dari apa yang ditulis oleh masing-masing peserta didik ditukar melalui system cross check. ${ }^{44}$

5) Peserta didik diminta untuk mempresentasikannya.

\section{PENUTUP}

Secara umum strategi pembelajaran terdiri atas lima komponen yang saling berinteraksi dengankarakter fungsi dalam mencapai tujuan pembelajaran, yaitu (1) kegiatan

\footnotetext{
${ }^{44}$ Menurut kamus Bahasa Asing-Bahasa Indonesia makna dari Cross check adalah memeriksa kembali, referensi diunduh dari internet kamuslengkap.com pada sabtu, 09 Desember 2017 pukul 20.00 Wib.
} 
pembelajaran pendahuluan, (2) penyampaian informasi, (3) partisipasi peserta didik, (4) tes, dan (5) kegiatan lanjutan. Pemilihan strategi pembelajaran hendaknya ditentukan berdasarkan kriteria berikut: (1) orientasistrategi pada tugas pembelajaran, (2) relevan dengan isi/materi pembelajaran, (3) metode dan teknikyang digunakan difokuskan pada tujuan yang ingin dicapai, dan (4) media pembelajaran yangdigunakan dapat merangsang indra peserta didik secara simultan. ${ }^{45}$

Hal tersebut diatas selaras dengan pembahasan mengenai inovasi strategi pembelajaran bahasa Arab Maharah Istima' (Keterampilan Menyimak) melalui beberapa strategi inovatif yakni Ta'lim Muta'awin تلخيص Talkhis Magza تبليم منعاو, Talka مغزى, Istima' mutabadilلإستماع متبادل, Istima' Al-Ghaniy Istima' Al-Ma'lumat Au Al-Akhbar إستماع المعلومات أو الأخبار Istima' Al-Musykilat إستماع المشكلات

45Syamsul Bakhri dan Djamarah, Strategi Belajar mengajar (Jakarta: Rineka Cipta 1997), hal. 15. Lihat juga TIMFIP IKIP Semarang,Strategi belajar Mengajar, hal. 10 


\section{DAFTAR PUSTAKA}

Basuni Imamuddin dkk. 2003. Kamus Idiom Arab-Indonesia Pola Aktif. Depok: Ulinnuha Press.

Dick Walter \& Carey Lou. 1994. The Systematic Desgn of Instruction. New York: Harper Collins publishers.

http://ithla-id.blogspot.co.id/2016/02/perbedaan-fushah-danamiah-dalam-bahasa.html

Kitab Al-Arabiyah li al-Nasyiin, jilid II dan III

Mahsun. 2005. Metode Penelitian Bahasa: Tahapan Strategi, Metode, dan Tehniknya. Jakarta: Rajawali Press.

Nana Sudjana. 1989. Dasar-Dasar Proses Belajar-MengajarBandung: Sinar Baru.

Radlyiyah Zaenuddin dkk. 2005. Metodologi dan Strategi Alternatif Pembelajaran Bahasa Arab. Yogyakarta: Pustaka Rihlah Group.

Sunhaji. 2008. Insania Volume 13, Nomor.3: “Strategi Pembelajaran: Konsep dan Aplikasinya". STAIN Purwokerto.

Syamsuddin Asyrofi dkk. 2006. Metodologi Pembelajaran Bahasa Arab. Yogyakarta: Pokja Akademik UIN Sunan Kalijaga Yogyakarta.

Syamsul Bakhri dan Djamarah. 1997. Strategi Belajar mengajar. Jakarta: Rineka Cipta. 